\title{
Meta-analysis of B-type natriuretic peptide in diagnosis of congestive heart failure in different clinical settings
}

This article was published in the following Dove Press journal:

Research Reports in Clinical Cardiology

30 November 2010

Number of times this article has been viewed

\section{Osama E Elkhateeb Iqbal Bata}

Simon Jackson

Dalhousie University, Halifax, Nova Scotia, Canada
Correspondence: Osama Elkhateeb Halifax Infirmary, 1796 Summer Street, Halifax, Nova Scotia, Canada B3H 3A7 Tel + I 902473333 I

Email osama.elkhateeb@cdha.nshealth.ca
Background: B-type natriuretic peptide (BNP) is a neurohormone released from the left ventricle in response to ventricular wall stress and pressure overload. BNP testing has been developed, and aids in identification of patients with suspected congestive heart failure (CHF). The objective of this study was to evaluate the role of BNP as a diagnostic marker of CHF, and determine its value in different clinical settings.

Methods: A systematic review and meta-analysis of clinical studies regarding BNP and CHF was conducted. A comprehensive search of Medline, the Cochrane Library, and the reference sections of the primary studies was done. The methodologic quality of each study that met the inclusion criteria was assessed. The results of individual studies were described. The pooled sensitivity and specificity were calculated. Estimation of the diagnostic accuracy was done using meta-regression of the diagnostic odds ratio and summarized by a summary receiver-operating curve (S-ROC).

Results: In total, 32 studies $(n=11054)$ met the inclusion criteria. The overall sensitivity and specificity at the optimum cutoff point are $81 \%$ (95\% confidence interval: $0.76-0.86)$ and $86 \%$ (95\% confidence interval: $0.81-0.89$ ), respectively. The area under the S-ROC for all studies is 0.92 . Nine papers included patients with dyspnea. The pooled negative likelihood ratio for this group was 0.12 . Five studies included patients with chronic $\mathrm{CHF}$ and another seven studies included patients who were referred for echocardiography. The remaining studies were patients from the general population, patients with stable coronary artery disease, and patients referred for cardiac catheterization.

Conclusion: BNP is a valuable tool in the diagnosis of CHF. It should be applied in the appropriate clinical setting. The strongest evidence of benefit for use of BNP is in patients presenting to the emergency room with dyspnea.

Keywords: B-type natriuretic peptide, congestive heart failure, neurohormone, summary receiver-operating curve, dyspnea

\section{Introduction}

Congestive heart failure (CHF) presently affects five million people in the US, and its diagnosis in frequently challenging. ${ }^{1}$ The prevalence of systolic dysfunction is $6 \%$. Fewer than half of the patients with moderate to severe diastolic or systolic dysfunction have recognized CHF. ${ }^{1}$ The number of newly diagnosed cases is increasing as the population ages. The incidence of CHF approaches 10 per 1000 population after the age of 65 years. Heart failure causes a huge burden on the health care system. For instance, in 2005 the estimated direct and indirect cost of CHF in the US was $\$ 27.9$ billion. $^{1}$ 
The natriuretic peptides are a group of structurally related peptides. ${ }^{2} \mathrm{C}$-type natriuretic peptide is a 22 -amino acid peptide produced mainly by the vascular endothelium. Atrial natriuretic peptide is a cyclic 28 -amino acid peptide secreted by the atria. B-type natriuretic peptide (BNP) first discovered in porcine brain, ${ }^{3}$ is a 32 -amino acid peptide that is structurally similar to atrial natriuretic peptide. It is mainly synthesized and secreted by both the atria and ventricles. When the wall of the ventricle is stretched in response to volume or pressure overload a prohormone, proBNP is cleaved by furin to form active $\mathrm{BNP}$ and inactive $\mathrm{N}$-terminal BNP molecules. These molecules are secreted into the circulation and then cleared by enzymatic- and receptor-mediated mechanisms. $^{2}$

A competitive radioimmune assay was the first method used for measurement of natriuretic peptides. This was followed by noncompetitive immunoradiometric assays, which are more precise and sensitive. ${ }^{4}$ More recently, a rapid point-of-care measurement of BNP was developed. It is fully automated and produces results in about 15 minutes, rather than up to 24 hours with the earlier methods. ${ }^{5}$

Several studies have been done to evaluate the measurement of BNP in CHF. A previous meta-analysis showed that there is significant heterogeneity among the studies. ${ }^{6,7}$ The aim of this meta-analysis was not only to determine the overall accuracy of BNP, but also to evaluate its value in different clinical settings. This will facilitate the use of the test in the appropriate clinical setting. Here we assess the methodologic quality of the studies, and synthesize the best available evidence.

\section{Methods}

\section{Literature review}

We performed a Medline and PubMed search from 1966 to April 2005 using a combination of search terms, ie, "brain natriuretic peptide", "proBNP", "BNP”, "B-type natriuretic peptide", and "CHF". A search of the Cochrane Library was conducted, and the reference sections of the relevant studies and reviews were manually searched.

\section{Study eligibility}

We included studies that evaluated BNP in the diagnosis of CHF. The BNP should be evaluated by comparing its results with a gold standard. Information should be available to allow construction of the diagnostic $2 \times 2$ table. We excluded studies that used $\mathrm{N}$-terminal BNP or atrial natriuretic peptide only. Because the main reason for our study was to evaluate the accuracy of BNP in the diagnosis of CHF, we excluded studies that evaluated asymptomatic patients with diastolic dysfunction. Furthermore, because it is well known that myocardial infarction increases BNP levels, we excluded all studies that included patients within 30 days of myocardial infarction.

\section{Data extraction}

We extracted data for the eligible studies using a standard format. This included total number of patients, demographic characteristics of patients, the reference test used, and the manufacturer of the BNP test. Specificity and sensitivity values, area under the receiver-operating curve, and the number of patients with true positive and true negative tests were abstracted. We then constructed the $2 \times 2$ table.

The methodologic quality of the studies was assessed using a checklist developed by Lijmer et al. ${ }^{8}$ We assessed the studies for selection bias as to whether the study was randomized or not. Verification bias was excluded if investigators were blinded to the results of the reference test, and if it was not clear from the text if the study was labeled as unblinded. The study was considered to be cross-sectional if the test was evaluated in patients known to have the disease and compared with healthy subjects. In addition, methods for data collection were categorized as either prospective or retrospective.

\section{Statistical analysis}

We described the results of individual studies. Heterogeneity in the results of the studies was assessed using the Chi-square test and Q-test. The pooled sensitivity and specificity was calculated using the random effect model. The summary receiver-operating curve (S-ROC) was performed using the methods described by Moses et $\mathrm{al}^{9}$ and the area under the S-ROC was calculated. A subgroup analysis was performed according to the clinical application of the test. Pooled specificity and sensitivity, and the S-ROC were calculated for each subgroup that included five or more studies. We also calculated the pooled likelihood ratios (LR) and the diagnostic odd ratios for the studies. Meta-Test version 0.6 ${ }^{10}$ and Meta-DiSc version 1.1.1 ${ }^{11}$ was used for the analysis.

\section{Results}

The strategy for the literature search is explained in Figure 1. More than 1500 citations were retrieved for the initial search from all sources. Of the 1500 citations we searched, the abstracts of 204 studies and 80 articles were identified for 


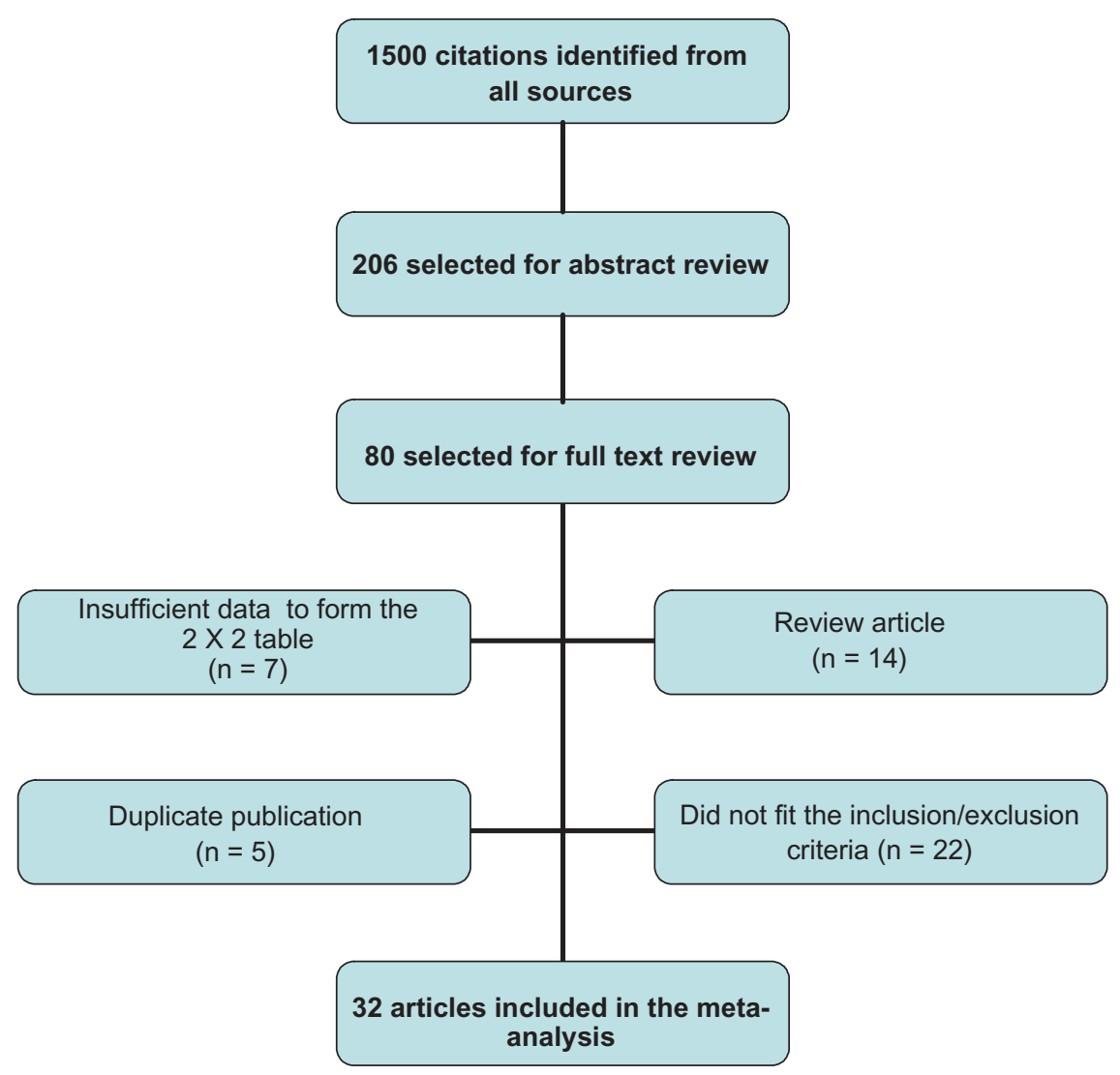

Figure I Strategy for literature search.

full text review. Of the 80 articles, seven were excluded because of insufficient information to form the $2 \times 2$ table, 14 were review articles, five were duplicate publications, and 22 articles did not fit the inclusion or the exclusion criteria. Finally we included 32 articles in the meta-analysis. ${ }^{12-43}$ The total number of patients included in all the studies was 11,054. The summary data for the studies included in the meta-analysis are shown in the Table 1 . The overall sensitivity and specificity at the optimum cutoff point as defined by the authors of each study was $81 \%$ (95\% confidence interval [CI]: 0.76-0.86) and 86\% (95\% CI: 0.81-0.89), respectively (Figure 2). The area under the S-ROC for all the studies was 0.92 (Figure 3).

\section{Subgroup analysis}

We divided the studies into eight distinct subgroups according to the clinical application of BNP (see Table 1). The pooled analysis was done to subgroups that had five or more studies included. Nine studies $(n=2943)$ evaluated patients presenting to the emergency department with dyspnea. Five studies $(n=3679)$ included patients with chronic CHF and another seven studies $(n=1359)$ included patients who were referred for echocardiography. The remaining studies were patients from the general population, patients with stable coronary artery disease, and patients referred for cardiac catheterization.

In the studies that evaluated patients presenting to the emergency department with dyspnea, the pooled sensitivity and specificity was $88 \%$ and $80 \%$, respectively. For patients with a history of CHF when compared with healthy subjects, the pooled specificity was $77 \%$ and $95 \%$ for sensitivity. The pooled sensitivity and specificity for patients referred for echocardiography was $85 \%$ and $77 \%$, respectively (Figure 4).

The pooled negative likelihood ratio was lowest for patients presenting to the emergency department with dyspnea at 0.12 . The positive likelihood ratio was highest for patients with a history of CHF, at 12.2 (Figure 5). The pooled diagnostic odd ratio for patients presenting to the emergency department with dyspnea was 48.53 and was highest for patients with history of $\mathrm{CHF}$, at 62.01 (Figure 6).

The area under the S-ROC was best for patients with a history of CHF at 0.96 ; for patient presenting to the emergency department with dyspnea it was 0.94, and for patients referred for echocardiography was 0.91 (Figure 7). 


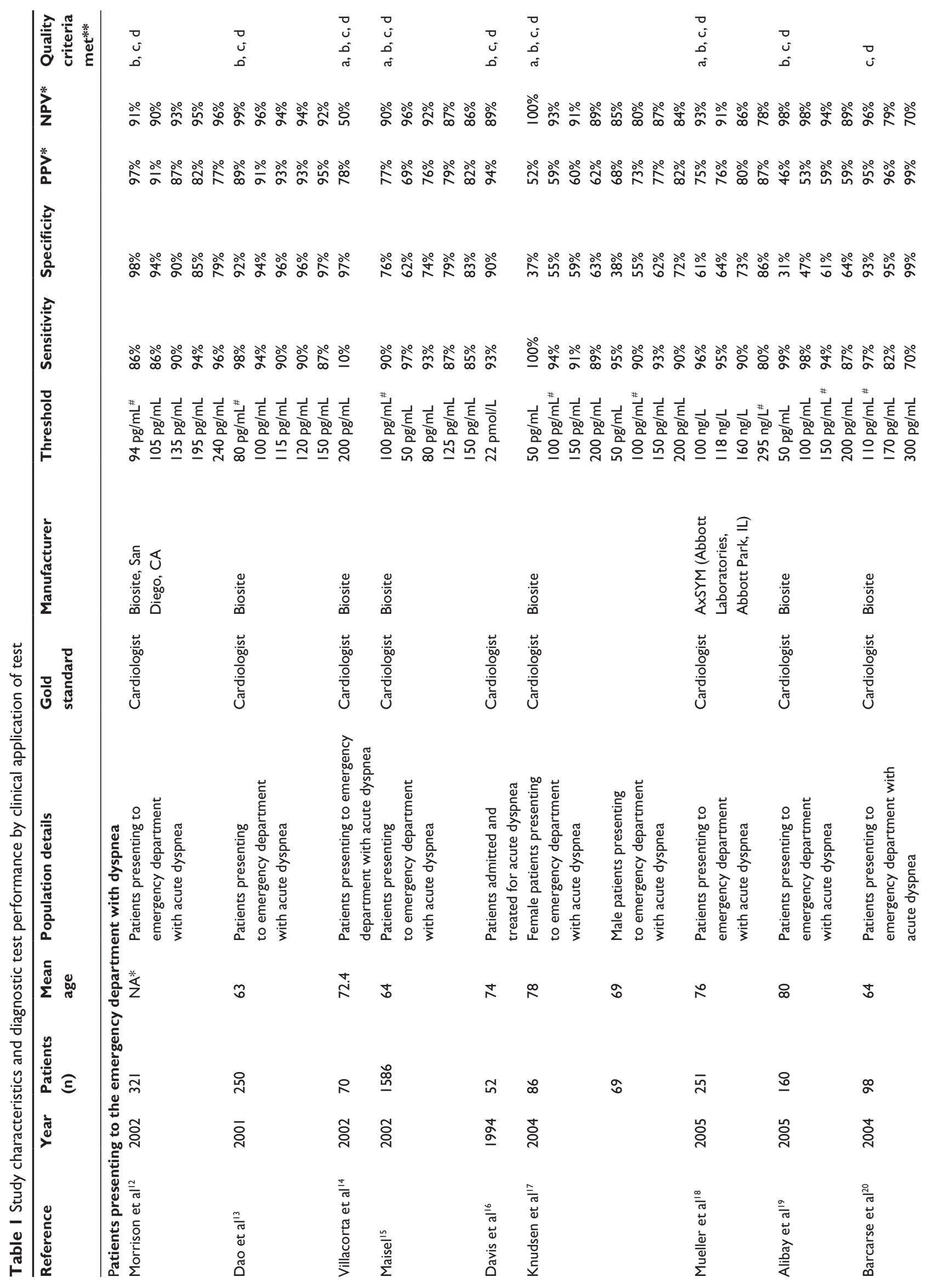




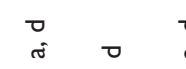

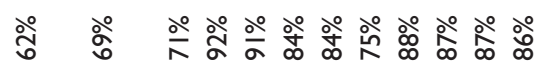

응 癹

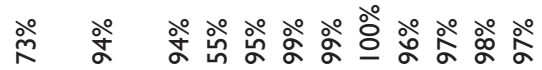

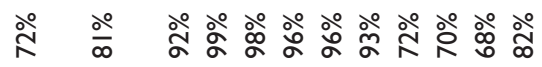

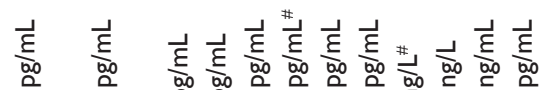

品

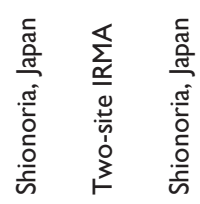

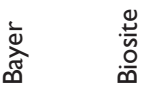

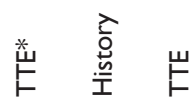
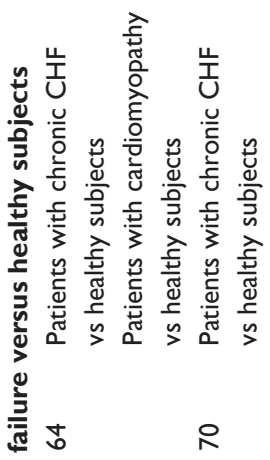

¿ّ

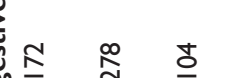

के

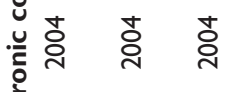

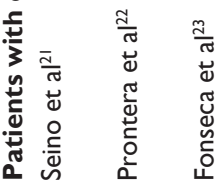

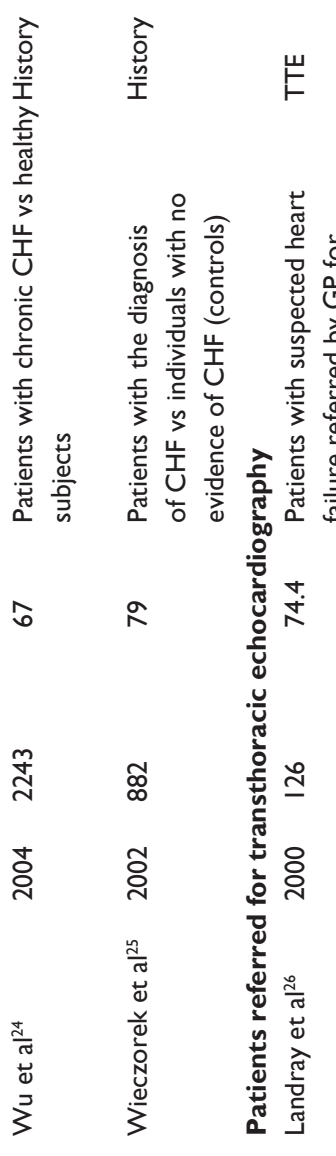

$\stackrel{m}{\mathrm{~F}}$

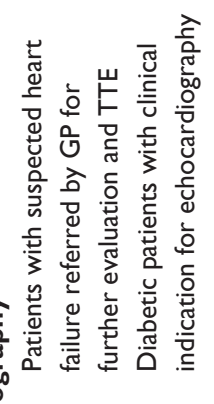

เั

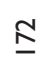

ஜ̊ํ

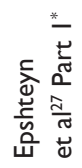

$\frac{\mathscr{4}}{\frac{0}{0}}$

$\stackrel{w}{F}$

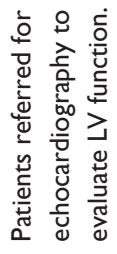

นก

우

유

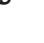

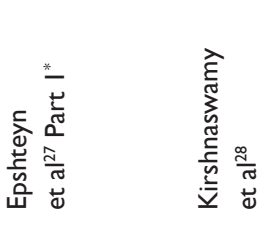

0
0
0
0
0

$\begin{array}{ll}2 & \text { a } \\ 0 & 0 \\ 0 & 0 \\ 0 & 0\end{array}$

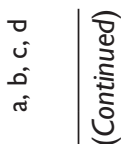

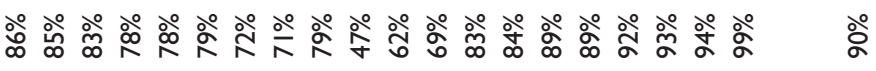

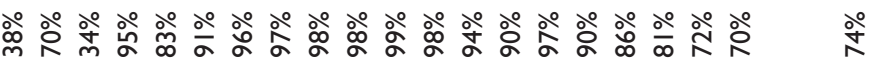

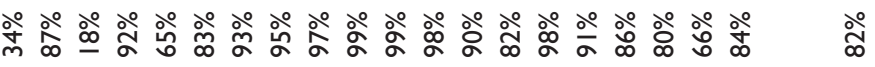

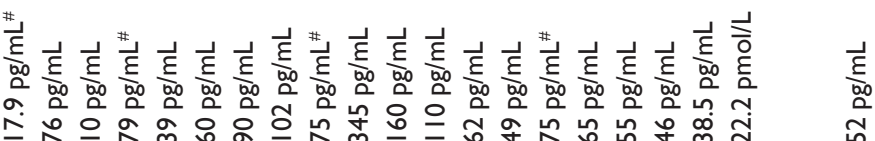

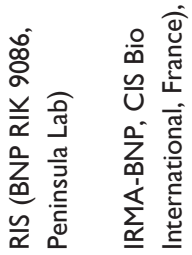

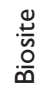

œ

$\stackrel{\mathrm{F}}{\mathrm{F}}$

$\sum_{3}^{\infty}$
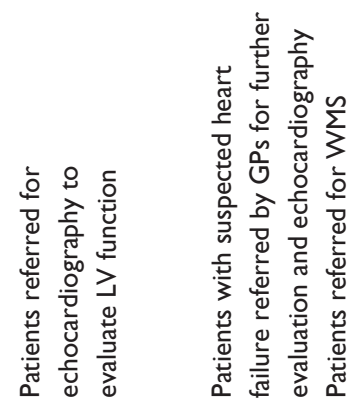

น

- in

ก

$\stackrel{0}{0}$

$\stackrel{ }{\underline{0}}$

$\overline{\mathrm{o}}$

ڤ

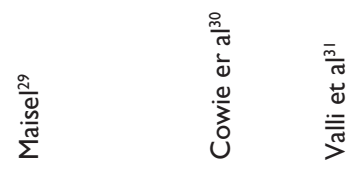




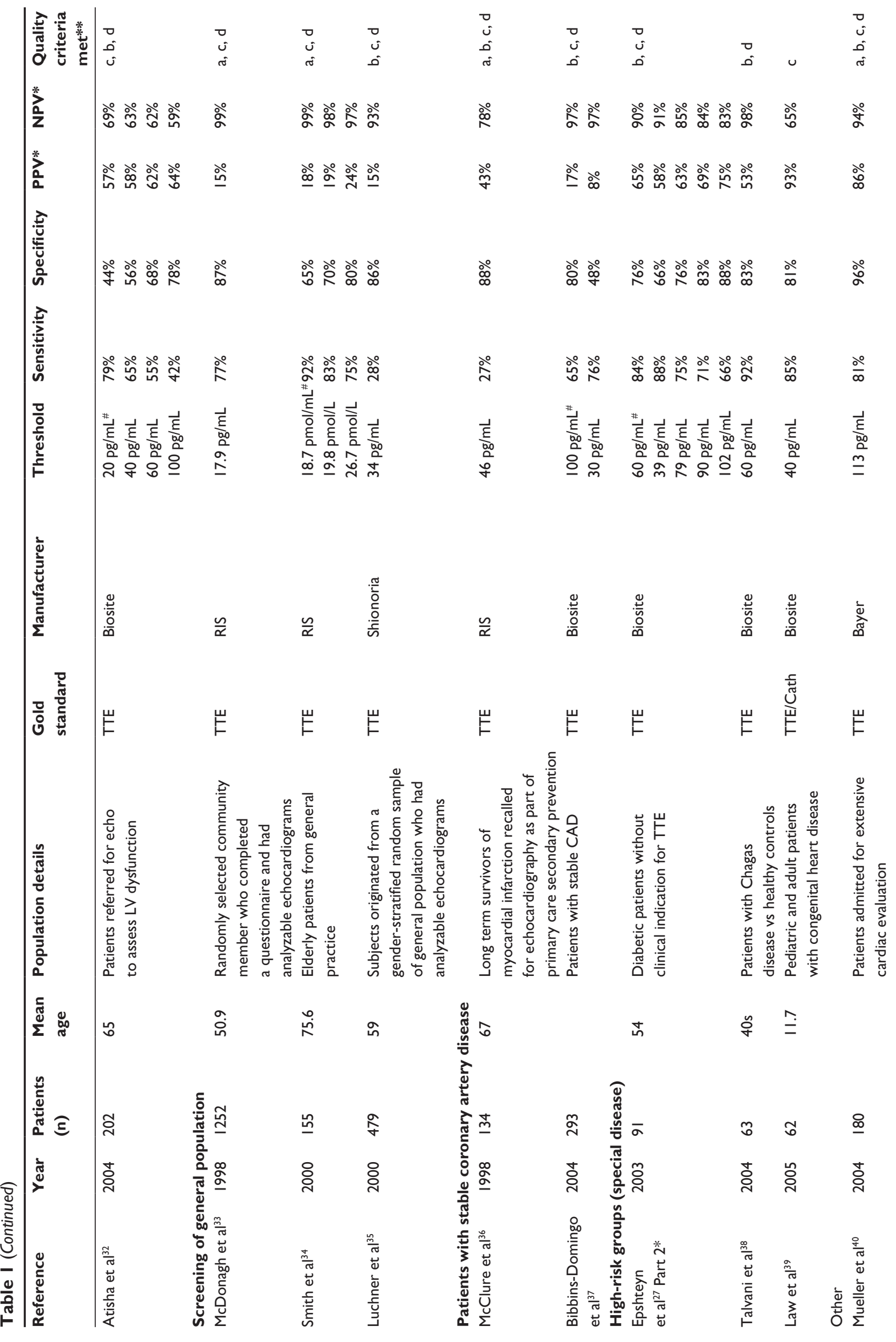




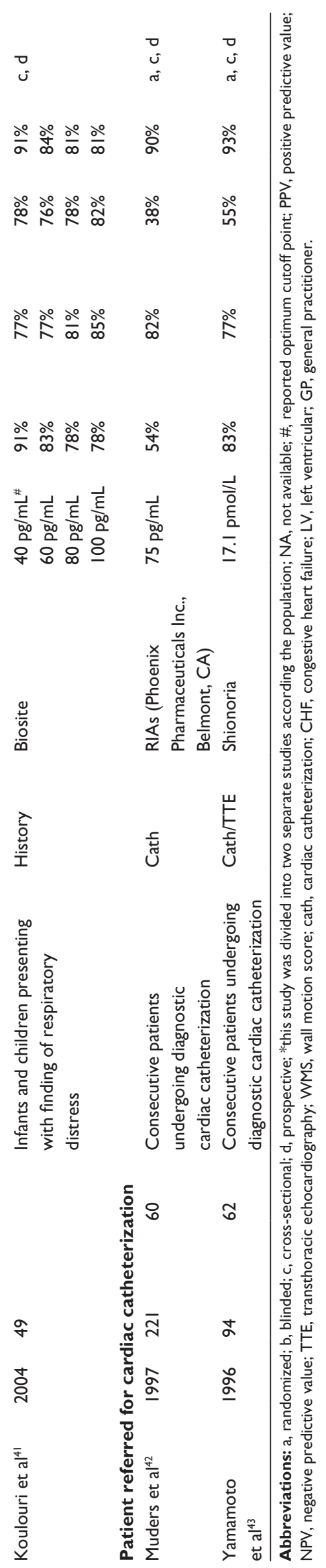

\section{Discussion}

In this metanalysis we showed that the overall sensitivity and specificity of BNP in the diagnosis of CHF was $81 \%$ and $86 \%$, respectively. Because of the heterogeneity among the studies, these results should be taken with caution, because pooling specificity and sensitivity might underestimate or overestimate the test accuracy. ${ }^{44}$ An alternative method to determine accuracy is the area under the S-ROC, which was 0.92 for all studies. Although the value of the S-ROC is difficult to interpret in the clinical setting, ${ }^{45}$ it indicates that the overall accuracy of the test is reasonable. To decrease the heterogeneity between the studies ${ }^{46}$ and to make the metaanalysis more clinically relevant, we divided the studies into eight different groups according to the clinical applications of BNP.

The largest group was patients who presented to the emergency department with dyspnea. This group included nine studies with a total of 2943 patients. More than $50 \%$ are from a single study known as the "Breathing Not Properly" study..$^{15}$ The pooled negative and positive likelihood ratios for patient presenting to the emergency department with dyspnea was 0.12 and 5.2, respectively. To put this into perspective, we used a theoretical patient who presented to the emergency department with shortness of breath of unknown cause. If his pretest probability was $40 \%$, the post-test probability of the test if it was positive would be $74 \%$, but, if the test was negative, it would be only $7 \%$. This indicates that BNP is more appropriate for ruling out rather than ruling in CHF in this clinical scenario. Several authors have arrived at the same conclusion, given the high sensitivity and negative predictive value of the test. ${ }^{47}$ Ruskoaho ${ }^{2}$ suggested that in those patients in whom the plasma BNP level is normal, other causes of dyspnea should be considered. Most of the studies used $80-100 \mathrm{pg} / \mathrm{mL}$ as the optimum cutoff point.

The BNP is more specific when healthy subjects are compared with patients having chronic CHF. The positive likelihood ratio is also higher at 12.2. This indicates that, in asymptomatic patients, a positive test is highly suspicious for CHF, although a negative test does not rule out the disease. Given the limited data in the studies, these results may not represent the true value. Furthermore, the application of these studies to clinical practice is uncertain.

For patients referred for assessment of LV function, the pooled specificity and sensitivity is not as good compared with the previous population. This may be as a result of variability between the studies. In addition the diagnostic odds ratio is also low, which indicates the poor diagnostic 


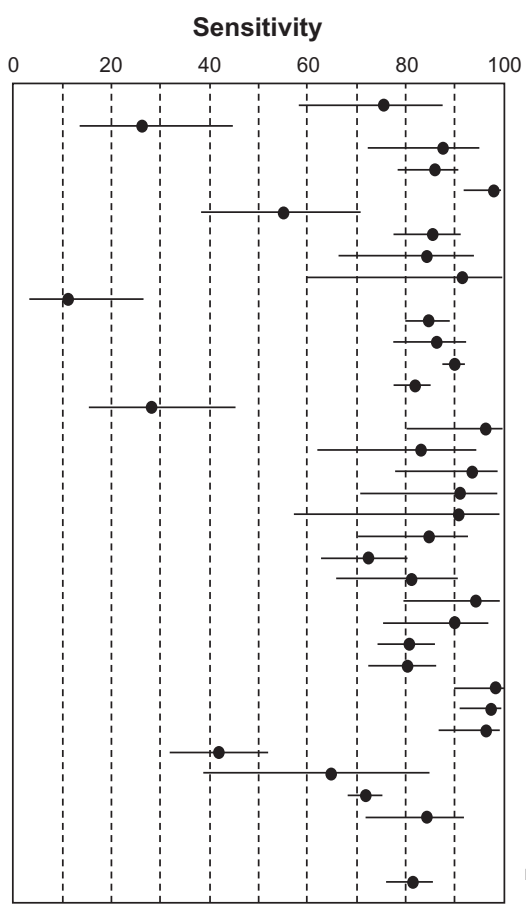

Heterogeneity Chi-squared $=\mathbf{4 5 9} .39$ Pooled sensitivity $=81 \%$

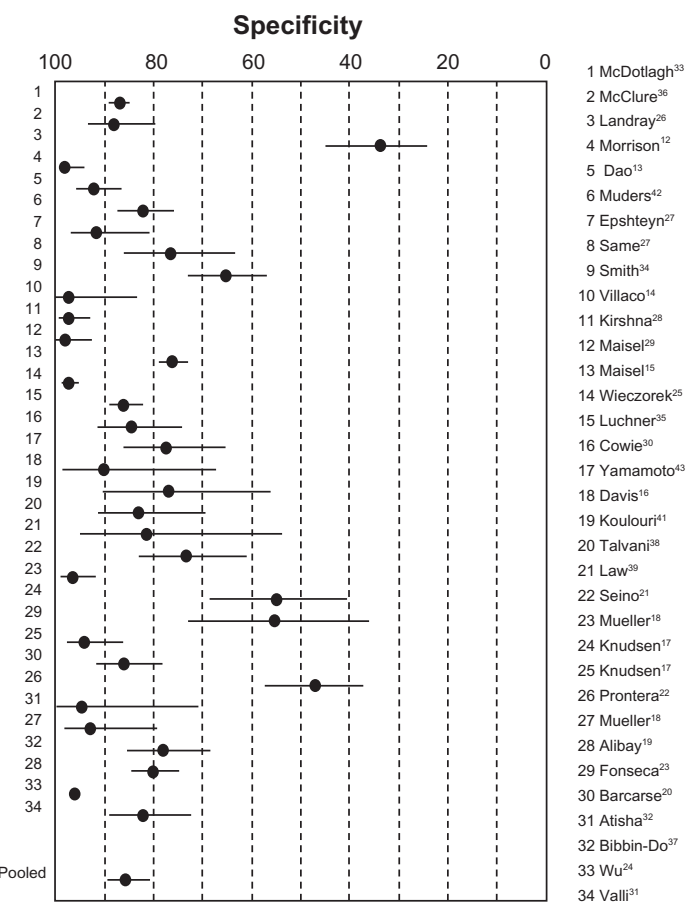

Heterogeneity Ch-squared $=\mathbf{6 8 5 . 0 5}$ Pooled specificity $=86 \%$

Figure 2 Pooled specificity and sensitivity for all studies ( $95 \%$ confidence interval) with Chi-square test for heterogeneity.

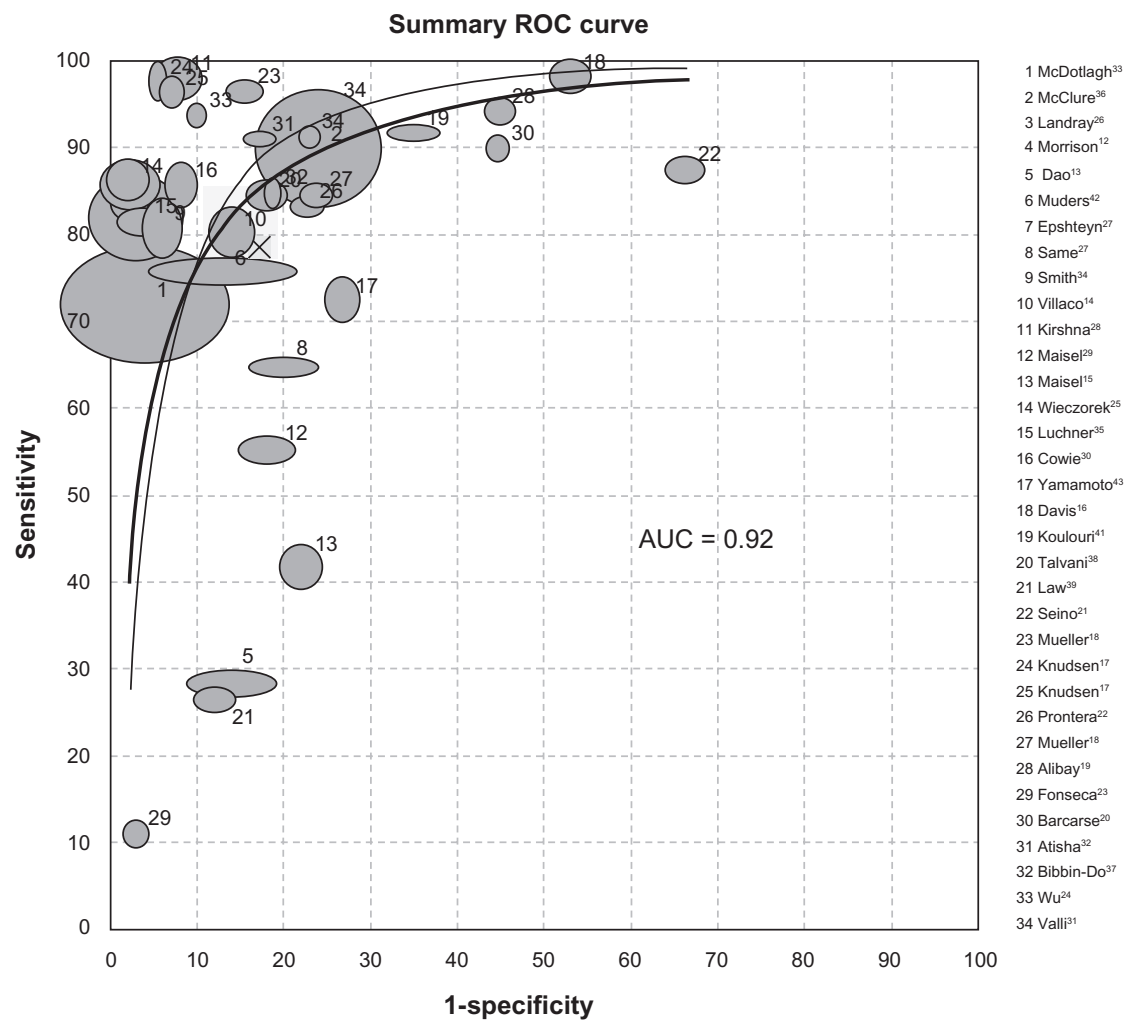

Figure 3 Summary receiver-operating curve for all studies $(n=34)$. Individual studies are depicated as ellipse. The $x$ and $y$ dimensions of the ellipses are proportional to the square root of the number of patients available to study the specificity and sensitivity, respectively, within the analysis. The cross ( $x$ ) represents the independent random effect pooling of sensitivity and specificity values of the studies. The numbers next to the ellipse represents the identification number for the study. The area under the concentration time-curve is 0.92 . 
A)
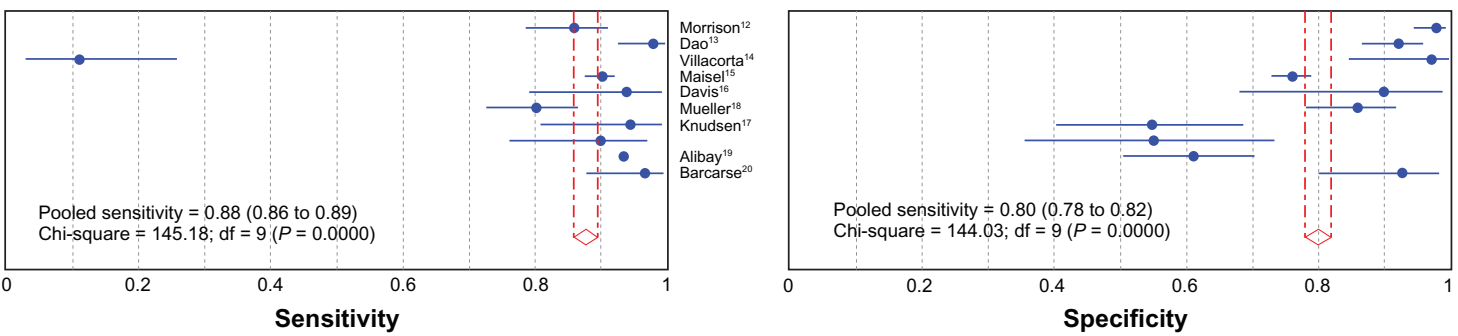

B)
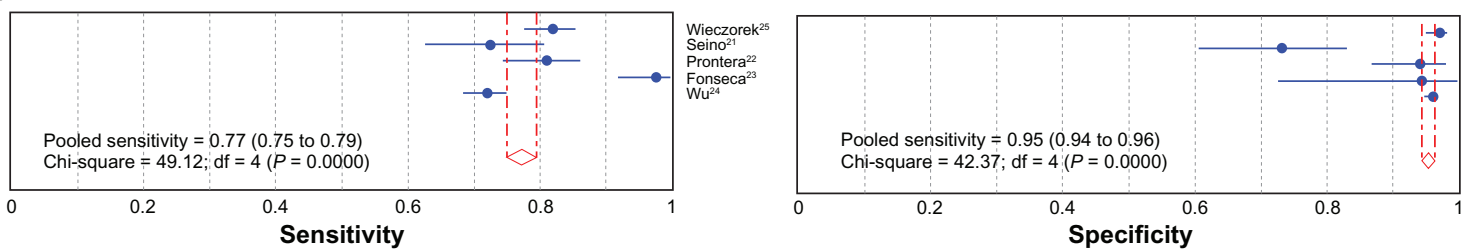

C)
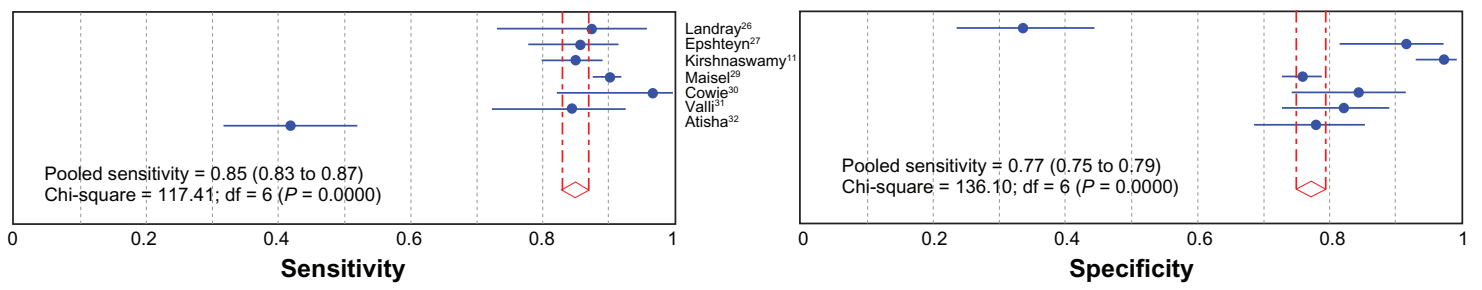

Figure 4 Pooled sensitivity and specificity (95\% confidence interval) for A) patients presenting to the emergency department with dyspnea, B) patients with chronic congestive heart failure versus healthy subjects, and $\mathbf{C}$ ) patients referred for echocardiography.

A)

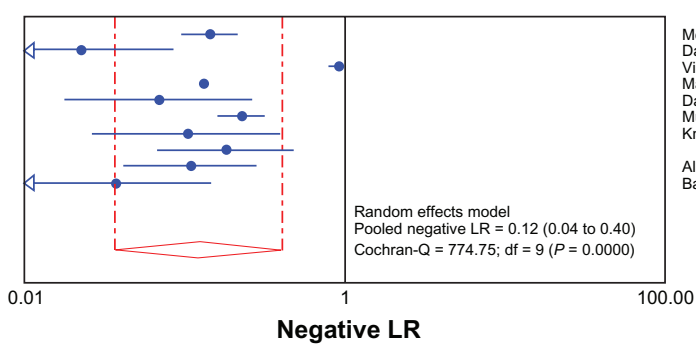

B)

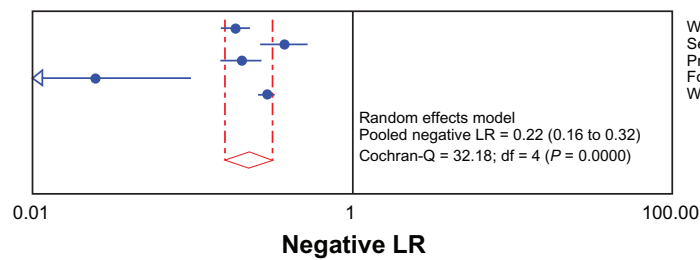

C)

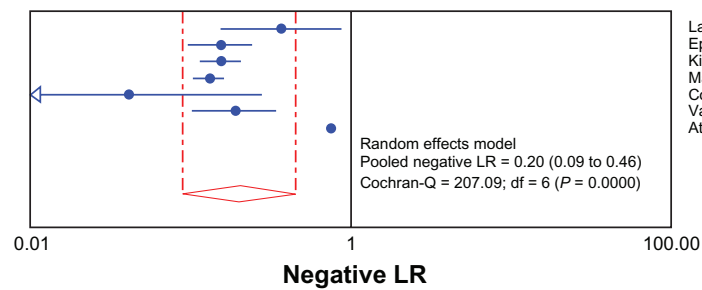

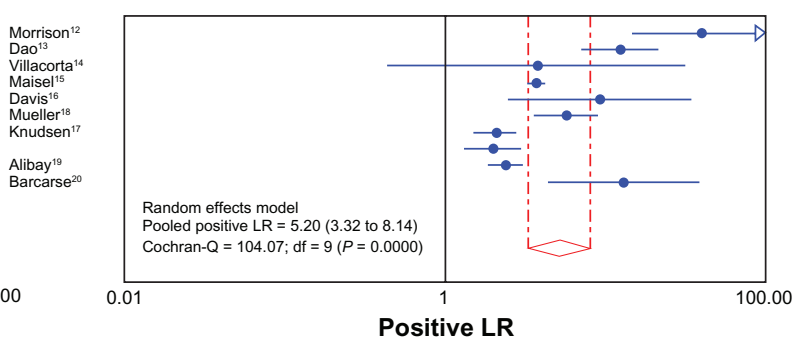
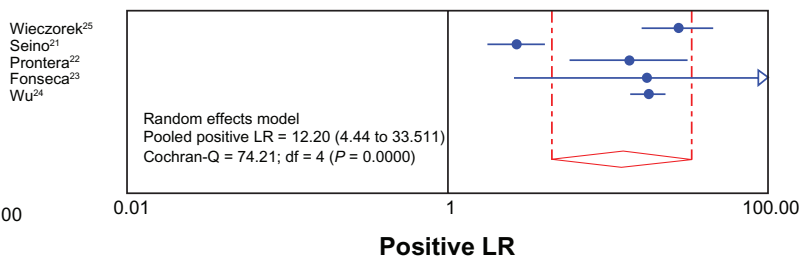

Positive LR

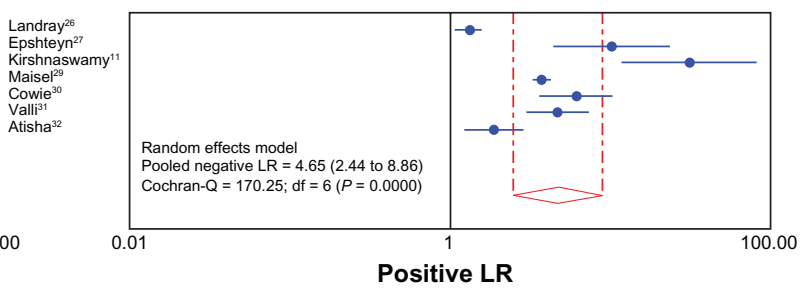

Figure 5 Positive and negative likelihood ratio ( $95 \%$ confidence interval) for A) patients presenting to the emergency department with dyspnea, B) patients with chronic congestive heart failure versus healthy subjects, and $\mathbf{C}$ ) patients referred for echo. 
A)

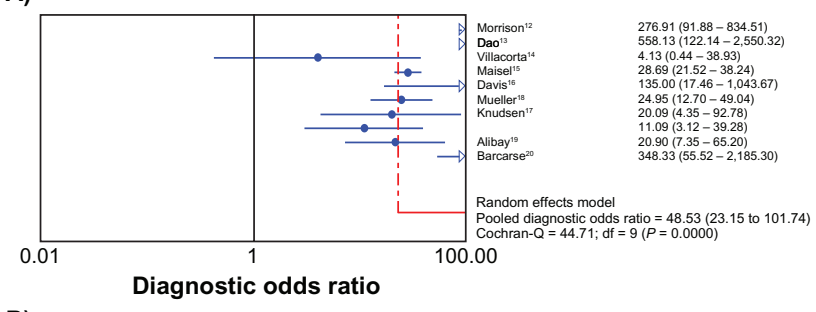

B)

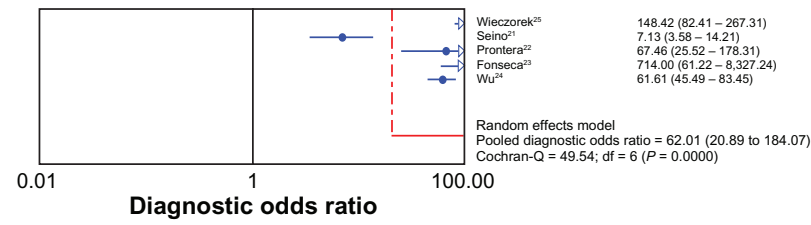

C)

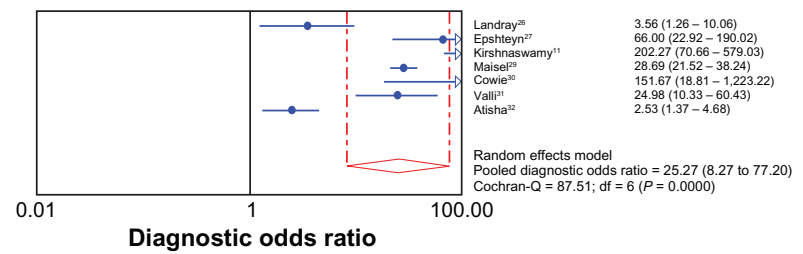

Figure 6 Pooled diagnostic odds ratio ( $95 \%$ confidence interval) for A) patients presenting to the emergency department with dyspnea, B) patients with chronic congestive heart failure versus healthy subjects, and C) patients referred for echocardiography.

accuracy of BNP in this clinical setting. This may be due to the fact that some studies included both symptomatic and asymptomatic patients. Another factor could be the type of practice of the referring physician.

The use of BNP as a screening tool in the general population was evaluated in three studies. The individual studies showed that BNP has a high negative predictive value. A value less than $50 \mathrm{pg} / \mathrm{mL}$ may have the best negative predictive value. Given the poor sensitivity and positive predictive value, BNP is not a useful screening tool for identifying patients with CHF.

A previous meta-analysis for BNP of CHF has been published. ${ }^{48}$ This included patients with diastolic dysfunction and patients with recent acute coronary syndrome. Furthermore it divided the studies according to the reference test used. In this review we excluded studies that evaluated patient with only diastolic dysfunction and recent acute coronary syndrome. Similar to this study, Mastandrea ${ }^{6}$ suggested that BNP could be more indicated for patients with acute CHF diagnosis. They concluded that the reference method used, disease prevalence, and degree of heart failure resulted in significant heterogeneity. Another study ${ }^{49}$ compared BNP with N-terminal proBNP. The overall BNP specificity and sensitivity was similar to that of our study, at $85 \%$ and $84 \%$, respectively. In this meta-analysis, we divided the studies into eight different subgroups according to the clinical application of the test. This facilitates the use and application of BNP to the appropriate patient population.

\section{Conclusion}

BNP is a valuable tool to aid in the diagnosis of CHF. It should be applied in the appropriate clinical setting. Based on the quality of the studies and the large number of patients, the best clinical evidence for use of BNP is available for patient presenting to the emergency department with symptomatic dyspnea. Further studies needed to evaluate BNP in additional patient groups, including asymptomatic or mildly symptomatic patients. BNP should be used in the right clinical setting in conjunction with other diagnostic tools to confirm CHF.
A)

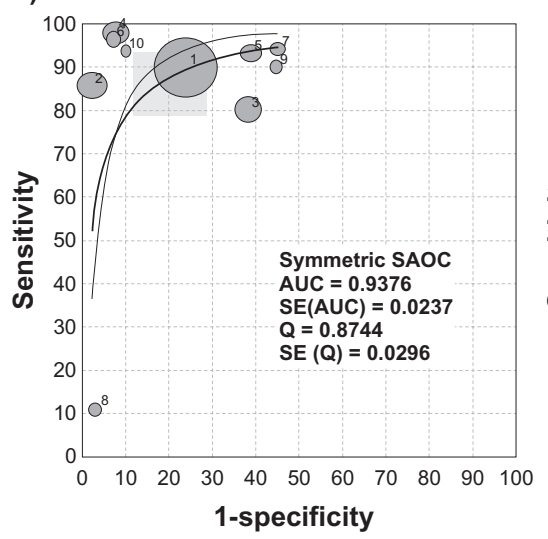

B)

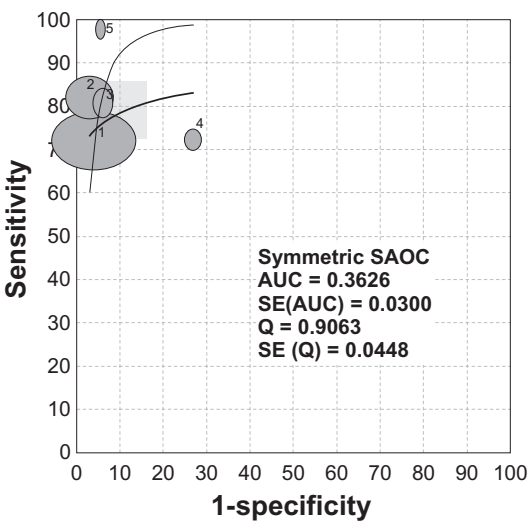

C)

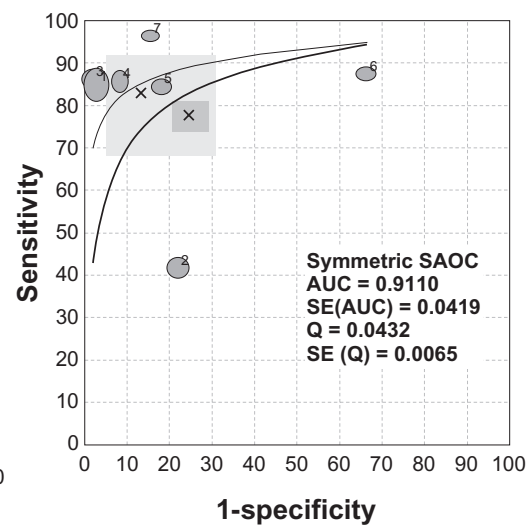

Figure 7 Summary receiver-operating curve for A) patients presenting to the emergency department with dyspnea, B) patients with chronic congestive heart failure versus healthy subjects, and $\mathbf{C}$ ) patients referred for echocardiography.

Abbreviations: AUC, area under the concentration-time curve; SE, standard error; $\mathrm{Q}^{*}, \mathrm{Q}^{*}$ index defined by the point where sensitivity and specificity are equal, which is the point closest to the ideal top left corner of the ROC space. 


\section{Disclosure}

The authors report no conflicts of interest in this work.

\section{References}

1. American Heart Association. Heart disease and stroke statistics -2005 update. Dallas, TX: American Heart Association; 2005. Available at: americanheart.org/statistics. Accessed 2010 Oct 12.

2. Ruskoaho H. Cardiac hormones as diagnostic tools in heart failure. Endocr Rev. 2003;24(3):341-356.

3. Sudoh T, Kangawa K, Minamino N, Matsuo H. A new natriuretic peptide in porcine brain. Nature. 1988;332(6159):78-81.

4. Clerico A, Del Ry S, Giannessi D. Measurement of cardiac natriuretic hormones (atrial natriuretic peptide, brain natriuretic peptide, and related peptides) in clinical practice: The need for a new generation of immunoassay methods. Clin Chem. 2000;46(10):1529-1534.

5. Silver MA, Maisel A, Yancy CW, et al. BNP Consensus Panel 2004: A clinical approach for the diagnostic, prognostic, screening, treatment monitoring, and therapeutic roles of natriuretic peptides in cardiovascular diseases. Congest Heart Fail. 2004;10 5 Suppl 3:1-30.

6. Mastandrea P. Some heterogeneity factors affecting the B-type natriuretic peptides outcome: A meta-analysis. Clin Chem Lab Med. 2008; 46(12):1687-1695.

7. Clerico A, Fontana M, Zyw L, Passino C, Emdin M. Comparison of the diagnostic accuracy of brain natriuretic peptide (BNP) and the N-terminal part of the propeptide of BNP immunoassays in chronic and acute heart failure: A systematic review. Clin Chem. 2007;53(5):813-822.

8. Lijmer JG, Mol BW, Heisterkamp S, et al. Empirical evidence of design-related bias in studies of diagnostic tests. JAMA. 1999;282(11): 1061-1066.

9. Moses LE, Shapiro D, Littenberg B. Combining independent studies of a diagnostic test into a summary ROC curve: Data-analytic approaches and some additional considerations. Stat Med. 1993;12(14):1293-1316.

10. New England Medical Center. Meta-Test program. 1997; Version 0.6.

11. XI Cochrane Colloquium. Meta-DiSc for Windows: A Software package for the Meta-analysis of Diagnostic Tests program. 2003; Version Beta 1.1.1.

12. Morrison LK, Harrison A, Krishnaswamy P, Kazanegra R, Clopton P, Maisel A. Utility of a rapid B-natriuretic peptide assay in differentiating congestive heart failure from lung disease in patients presenting with dyspnea. J Am Coll Cardiol. 2002;39(2):202-209.

13. Dao Q, Krishnaswamy P, Kazanegra R, et al. Utility of B-type natriuretic peptide in the diagnosis of congestive heart failure in an urgent-care setting. J Am Coll Cardiol. 2001;37(2):379-385.

14. Villacorta H, Duarte A, Duarte NM, et al. The role of B-type natriuretic peptide in the diagnosis of congestive heart failure in patients presenting to an emergency department with dyspnea. Arq Bras Cardiol. 2002; 79(6):569-572.

15. Maisel AS, Krishnaswamy P, Nowak RM, et al. Rapid measurement of B-type natriuretic peptide in the emergency diagnosis of heart failure. N Engl J Med. 2002;347(3):161-167.

16. Davis M, Espiner E, Richards G, et al. Plasma brain natriuretic peptide in assessment of acute dyspnoea. Lancet. 1994;343(8895):440-444.

17. Knudsen CW, Riis JS, Finsen AV, et al. Diagnostic value of a rapid test for B-type natriuretic peptide in patients presenting with acute dyspnoea: Effect of age and gender. Eur J Heart Fail. 2004;6(1):55-62.

18. Mueller C, Laule-Kilian K, Christ A, Staub D. The use of B-type natriuretic peptide in the diagnosis of acute dyspnoea. Clin Lab. 2005; 51(1-2):5-9.

19. Alibay Y, Beauchet A, El Mahmoud R, et al. Plasma N-terminal probrain natriuretic peptide and brain natriuretic peptide in assessment of acute dyspnea. Biomed Pharmacother. 2005;59(1-2):20-24.

20. Barcarse E, Kazanegra R, Chen A, Chiu A, Clopton P, Maisel A. Combination of B-type natriuretic peptide levels and non-invasive hemodynamic parameters in diagnosing congestive heart failure in the emergency department. Congest Heart Fail. 2004;10(4):171-176.
21. Seino Y, Ogawa A, Yamashita T, et al. Application of NT-proBNP and BNP measurements in cardiac care: A more discerning marker for the detection and evaluation of heart failure. Eur J Heart Fail. 2004; 6(3):295-300.

22. Prontera C, Emdin M, Zucchelli GC, Ripoli A, Passino C, Clerico A. Analytical performance and diagnostic accuracy of a fully-automated electrochemiluminescent assay for the N-terminal fragment of the pro-peptide of brain natriuretic peptide in patients with cardiomyopathy: Comparison with immunoradiometric assay methods for brain natriuretic peptide and atrial natriuretic peptide. Clin Chem Lab Med. 2004;42(1):37-44.

23. Fonseca C, Sarmento PM, Minez A, et al. Comparative value of BNP and NT-proBNP in diagnosis of heart failure. Rev Port Cardiol. 2004; 23(7-8):979-991.

24. Wu AH, Packer M, Smith A, et al. Analytical and clinical evaluation of the Bayer ADVIA Centaur automated B-type natriuretic peptide assay in patients with heart failure: A multisite study. Clin Chem. 2004; 50(5):867-873.

25. Wieczorek SJ, Wu AH, Christenson R, et al. A rapid B-type natriuretic peptide assay accurately diagnoses left ventricular dysfunction and heart failure: A multicenter evaluation. Am Heart J. 2002;144(5): 834-839.

26. Landray MJ, Lehman R, Arnold I. Measuring brain natriuretic peptide in suspected left ventricular systolic dysfunction in general practice: Cross-sectional study. BMJ. 2000;320(7240):985-986.

27. Epshteyn V, Morrison K, Krishnaswamy P, et al. Utility of B-type natriuretic peptide (BNP) as a screen for left ventricular dysfunction in patients with diabetes. Diabetes Care. 2003;26(7):2081-2087.

28. Krishnaswamy P, Lubien E, Clopton P, et al. Utility of B-natriuretic peptide levels in identifying patients with left ventricular systolic or diastolic dysfunction. Am J Med. 2001;111(4):274-279.

29. Maisel A. B-type natriuretic peptide levels: A potential novel "white count" for congestive heart failure. J Card Fail. 2001;7(2):183-193.

30. Cowie MR, Struthers AD, Wood DA, et al. Value of natriuretic peptides in assessment of patients with possible new heart failure in primary care. Lancet. 1997;350(9088):1349-1353.

31. Valli N, Georges A, Corcuff JB, Barat JL, Bordenave L. Assessment of brain natriuretic peptide in patients with suspected heart failure: Comparison with radionuclide ventriculography data. Clin Chim Acta. 2001;306(1-2):19-26.

32. Atisha D, Bhalla MA, Morrison LK, et al. A prospective study in search of an optimal B-natriuretic peptide level to screen patients for cardiac dysfunction. Am Heart J. 2004;148(3):518-523.

33. McDonagh TA, Robb SD, Murdoch DR, et al. Biochemical detection of left-ventricular systolic dysfunction. Lancet. 1998;351(9095):9-13.

34. Smith H, Pickering RM, Struthers A, Simpson I, Mant D. Biochemical diagnosis of ventricular dysfunction in elderly patients in general practice: Observational study. BMJ. 2000;320(7239): 906-908.

35. Luchner A, Burnett JC Jr, Jougasaki M, et al. Evaluation of brain natriuretic peptide as marker of left ventricular dysfunction and hypertrophy in the population. J Hypertens. 2000;18(8):1121-1128.

36. McClure SJ, Caruana L, Davie AP, Goldthorp S, McMurray JJ. Cohort study of plasma natriuretic peptides for identifying left ventricular systolic dysfunction in primary care. BMJ. 1998;317(7157): 516-519.

37. Bibbins-Domingo K, Ansari M, Schiller NB, Massie B, Whooley MA. Is B-type natriuretic peptide a useful screening test for systolic or diastolic dysfunction in patients with coronary disease? Data from the Heart and Soul Study. Am J Med. 2004;116(8):509-516.

38. Talvani A, Rocha MO, Cogan J, et al. Brain natriuretic peptide and left ventricular dysfunction in chagasic cardiomyopathy. Mem Inst Oswaldo Cruz. 2004;99(6):645-649.

39. Law YM, Keller BB, Feingold BM, Boyle GJ. Usefulness of plasma B-type natriuretic peptide to identify ventricular dysfunction in pediatric and adult patients with congenital heart disease. Am J Cardiol. 2005; 95(4):474-478. 
40. Mueller T, Gegenhuber A, Poelz W, Haltmayer M. Biochemical diagnosis of impaired left ventricular ejection fraction - comparison of the diagnostic accuracy of brain natriuretic peptide (BNP) and amino terminal proBNP (NT-proBNP). Clin Chem Lab Med. 2004;42(2):159-163.

41. Koulouri S, Acherman RJ, Wong PC, Chan LS, Lewis AB. Utility of B-type natriuretic peptide in differentiating congestive heart failure from lung disease in pediatric patients with respiratory distress. Pediatr Cardiol. 2004;25(4):341-346.

42. Muders F, Kromer EP, Griese DP, et al. Evaluation of plasma natriuretic peptides as markers for left ventricular dysfunction. Am Heart J. 1997;134(3):442-449.

43. Yamamoto K, Burnett JC Jr, Jougasaki M, et al. Superiority of brain natriuretic peptide as a hormonal marker of ventricular systolic and diastolic dysfunction and ventricular hypertrophy. Hypertension. 1996; 28(6):988-994.

44. Irwig L, Tosteson AN, Gatsonis C, et al. Guidelines for meta-analyses evaluating diagnostic tests. Ann Intern Med. 1994;120(8):667-676.
45. Deeks JJ. Systematic reviews in health care: Systematic reviews of evaluations of diagnostic and screening tests. BMJ. 2001;323(7305): 157-162.

46. Tatsioni A, Zarin DA, Aronson N, et al. Challenges in systematic reviews of diagnostic technologies. Ann Intern Med. 2005;142(12 Pt 2): 1048-1055.

47. Maisel A. B-type natriuretic peptide measurements in diagnosing congestive heart failure in the dyspneic emergency department patient. Rev Cardiovasc Med. 2002;3 Suppl 4:S10-S17.

48. Doust JA, Glasziou PP, Pietrzak E, Dobson AJ. A systematic review of the diagnostic accuracy of natriuretic peptides for heart failure. Arch Intern Med. 2004;164(18):1978-1984.

49. Ewald B, Ewald D, Thakkinstian A, Attia J. Meta-analysis of B type natriuretic peptide and $\mathrm{N}$-terminal pro B natriuretic peptide in the diagnosis of clinical heart failure and population screening for left ventricular systolic dysfunction. Intern Med J. 2008;38(2): 101-113.

\section{Research Reports in Clinical Cardiology}

\section{Publish your work in this journal}

Research Reports in Clinical Cardiology is an international, peerreviewed, open access journal publishing original research, reports, editorials, reviews and commentaries on all areas of cardiology in the clinic and laboratory. The manuscript management system is completely online and includes a very quick and fair peer-review system. Visit

\section{Dovepress}

http://www.dovepress.com/testimonials.php to read real quotes from published authors. 